\title{
Effect of Sport Activity on Elderly Hypokinetic Trend and Risk
}

\author{
Nurlan Kusmaedi* \\ Faculty of Sport and Health Education \\ Universitas Pendidikan Indonesia \\ Bandung, Indonesia \\ *nurlan.kusmaedi@upi.edu
}

\begin{abstract}
The purpose of the present study was to measure hypokinetic trend and risk status of the elderly who active in five kinds of sport; and to describe the difference of training effect of five kinds of sport to elderly hypokinetic trend and risk. The expost facto method was used for this study. Subjects who participated in the study were seventy-four elderly people, and their five respective sport health club situated in Bandung, id Est lawn tennis (12), walking (16), table tennis (13), gymnastic (15), badminton (15). The instrument used to measure sport activity refers to the physical fitness test proposed by the Center for Study and Development of Sports Science and Technology Office of the Minister of Youth and Sports, and a interviewed questionnaire for hypokinetic. Hypokinetic trends measurement with 15 questions, risk of hypokinetic with 10 questions. SPSS 2014 was used for data analyze. The result of this study was: 1. The hypokinetic status rank according to gain score was: badminton, lawn tennis, gymnastic, walking, table tennis, all of them were on good status; 2 . The risk status of ache because of hypokinetic according to gain score was: badminton, lawn tennis, table tennis, gymnastic, walking. Conclusions: The activity of five kinds of sport give good effect as an effort to overcome less movement quality and give very good effect as an preventif effort to hypokinetic trend and risk.
\end{abstract}

Keywords—sport activity; health and physical fitness; hypokinetic trend and risk

\section{INTRODUCTION}

Health and physical fitness of a person definitely dropped with age, fitness level declines with age but probably not at the uniform rate, and a significant decrease in physical fitness occurs with advancing age, especially in those abilities that are related to mobility and risk for falls. The age of 70-80 years seems to be a critical period of life [1] and FF $10-15 \%$ per decade in individuals aged 60-94 years [2].

Health and physical fitness can be obtained by means of physical activity programmed according to ability and age. Conversely, if less physical activity plus overeating or snacking can cause hypokinetic. Physical activity that can be used is to do sports activities tennis, walking, table tennis, aerobics, badminton. Each sport has specific characteristics or abilities dominant components of fitness required to do so. Physical activity through sport exercise is an activity that is very effective for preventing various risks as a result of the continued hypokinetic. Hypokinetic or lack of physical activity or exercise can trigger a variety of serious illnesses in the body. Hypokinetic can be overcome or prevented by physical activity in accordance with one's abilities and needs, as expressed by Giriwijoyo, that adequate physical activity reduces the risk of early death, death by heart disease, the occurrence of diabetes mellitus, the hypertension disease, the occurrence of colon cancer, the disease of depression and anxiety, impaired bone health, muscles, joints, and the mental disorder [3]. Manson et al., also describes that "Physical activity (PA) has been shown to be effective in the prevention and management of cardiovascular disease, stroke, hypertension, breast cancer, colon cancer, type 2 diabetes and osteoporosis" [4]. Hypokinetic risk can also be inhibited by doing aerobic physical activity, such as disclosed in Jan Lexell, "Elderly men and women can improve their aerobic fitness and endurance as well as balance, strength and flexibility up to a very advanced age. Aerobic exercise can affect risk factors for cardiovascular disease" [5].

Many of elderly people do not understand, that sport activities where is managing well can become a physical activity to increase recorded/measured physical fitness. There are many sport activity, but it is important to choose one of sport activities which is adapt to elderly ability and age. It is better for elderly to do sport activities which have done for along time before, so that it is very easy of implementation. Beside that, the elderly skill and physical fitness level not from the beginning.

To know in what level or status is the elderly physical fitness, and how are the effect of sport activity to maintain the quality of movement degradation, it's needed to measure or to test with valid instrument.

Some purpose of this study are:

- to reveal the differences in the effect of sport activities of lawn tennis, walking, table tennis, gymnastics, badminton on the status of hypokinetic of ther elderly;

- to reveal the differences in the effect of sport activities of lawn tennis, walking, table tennis, gymnastics, badminton against the trends and risk of hypokinetic of the elderly. 
Hypothesis of this study are:

There are significant differences in the effect of exercise activity of tennis courts, walking, table tennis, gymnastics, badminton against: hypokinetic trends and risk. rend.

\section{METHOD}

The method used is' expost facto 'by design' the five parallel static group posttest design ". The sample was 74 people a members of five elderly sports clubs, with details of 12 tennis courts, walking 16, table tennis 13 , gymnastics 15 , badminton 15 . Independent variables are denoted by the letter $\mathrm{X}$ in this study is a sports activity tennis courts (X1), walking (X2), table tennis (X3), gymnastics (X4), badminton (X5). Dependent variable is denoted by the letter $\mathrm{Y}$ is hypokinetic which is divided into two components, the physical fitness (Y1), and hypokinetic (Y2).

Of the two methods of measurement of physical fitness as stated by Mood DP, et al, that "Physical fitness can be directly Measured with either laboratory or field methods" [6], this study uses "field methods" the instrument used to measure sport activity refers to the physical fitness test proposed by the Center for Study and Development of Sports Science and Technology Office of the Minister of Youth and Sports, and a interviewed questionnaire for hypokinetic. The difference in the effect of the activity of each sport activity against hypokinetic using one way anova with SPSS 18 for windows. Hypokinetic trends measurement with 15 questions, risk of hypokinetic with 10 questions.

\section{RESULTS AND DiSCUSSION}

Statistical analysis techniques were used to test the first and second hypothesis is the one-way ANOVA using the computer program SPSS 18 for window. Before testing the hypothesis one-way ANOVA is used, there are some prerequisite testing called statistical hypotheses testing. Prerequisite test include tests of normality and homogeneity tests. If the data were normally distributed and homogeneous, the hypothesis testing can be continued by using statistical parametric one-way ANOVA.

TABLE I. RESULTS OF ONE WAY ANOVA

\begin{tabular}{|c|c|l|c|c|c|}
\hline \multicolumn{7}{|c|}{ HYPOKINETIC } \\
\hline & $\begin{array}{c}\text { Sum of } \\
\text { Squares }\end{array}$ & $\boldsymbol{d f}$ & $\begin{array}{c}\text { Mean } \\
\text { Square }\end{array}$ & $\boldsymbol{F}$ & Sig. \\
\hline $\begin{array}{c}\text { Between } \\
\text { Groups }\end{array}$ & 2050,677 & 4 & 512,669 & 1,369 &, 254 \\
\hline $\begin{array}{c}\text { Within } \\
\text { Groups }\end{array}$ & 25832,188 & 69 & 374,380 & & \\
\hline Total & 27882,865 & 73 & & & \\
\hline
\end{tabular}

Based on the table 1 above, note that the value of sig. 0.254 $<0.05$ thus Ho as they arrive. Thus there is no difference between the average Hypokinetic group exercise sports activities tennis courts, a health walk, table tennis, aerobics, badminton and telecom.
The hypokinetic status of members who follows lawn tennis activity is good (22.67), it means that lawn tennis activities have good effect to the quality of movement degradation. The status of hypokinetic risk is excellent (4.91), it means that the activity of lawn tennis provide excellent effect as a preventive against the possibility of the hypokinetic risk. Overall lawn tennis ac. tivities provide good effect (27.58) to hypokinetic trend and as a preventive against hypokinetic risk or desease.

The hypokinetic status of members who follows walking activity is good (25.25), it means that walking activities have good effect to the quality of movement degradation. The status of hypokinetic risk is excellent $(5,31)$, it means that the activity of walking provide excellent effect as a preventive against the possibility of the hypokinetic risk. Overall walking activities provide good effect $(30,56)$ to hypokinetic trend and as a preventive against hypokinetic risk or desease

The hypokinetic status of members who follows table tennis activity is good $(27,30)$, it means that table tennis activities have good effect to the quality of movement degradation. The status of hypokinetic risk is excellent $(5,15)$, it means that the activity of table tennis provide excellent effect as a preventive against the possibility of the hypokinetic risk. Overall table tennis activities provide good effect $(32,46)$ to hypokinetic trend and as a preventive against hypokinetic risk or desease

The hypokinetic status of members who follows gymnastic activity is good $(25,2)$, it means that gymnastic activities have good effect to the quality of movement degradation. The status of hypokinetic risk is excellent $(5,27)$, it means that the activity of table tennis provide excellent effect as a preventive against the possibility of the hypokinetic risk. Overall table tennis activities provide good effect $(30,47)$ to hypokinetic trend and as a preventive against hypokinetic risk or desease

The hypokinetic status of members who follows badminton activity is good $(19,67)$, it means that badminton activities have good effect to the quality of movement degradation. The status of hypokinetic risk is excellent $(2,33)$, it means that the activity of table tennis provide excellent effect as a preventive against the possibility of the hypokinetic risk. Overall table tennis activities provide good effect (22) to hypokinetic trend and as a preventive against hypokinetic risk or desease

Overall the hypokinetic status of all members who follows five sports activities id est lawn tennis, walking, table tennis, gymnastics, and badminton is good (24.02), it means that all of five sport activities have good effect to the quality of movement degradation. The status of hypokinetic risk is excellent $(4,59)$, it means that all of five sport activities provide excellent effect as a preventive against the possibility of the hypokinetic risk. Overall all of five sport activities provide good effect (22) to hypokinetic trend and as a preventive against hypokinetic risk or desease

Based on the gain scores, the rank of hypokinetic status influenced by the five sport activities are badminton (19.67/ Good status), lawn tennis (22.67/ Good status), gymnastics (25.2/ Good status), walking (25.25/ Good status), table tennis (27.30/ Good status). 
Based on the gain scores due to the status of hypokinetic risk influenced by five sports activities are badminton (2.33/ Excellent), lawn tennis (4.91/ Excellent), table tennis (5.15/ BS), gymnastics (5.27/ Excellent), walking (5.31/ Excellent).

Based on the combined of gain scores due to hipokinetic trend and risk status influenced by five sports activities are badminton (22/ Excellent), lawn tennis (27.58/ Good), gymnastics (30.47/ Good), walking (30.56/ Good), table tennis (32.46/ Good).

Overall the results of health-related physical fitness test, skill related physical fitness test, and hypokinetic trend and risk is expected to be useful as a feedback for further designing programs, maintaining good status, to improve the poor status, according to the ability of elderly individuals, respectively. This is consistent with the proposed by Suni, JH, et al. "The ultimate purpose is to give feedback to the individual in terms of the adequacy of his or her fitness with regard to health criteria. Although our results provide some elements for the development of such criteria" [7]. On the other hand Arazi, H., et al. states in his research conclusion that "The ability to maintain repetitions and to perform a higher volume of training has been shown to be essential for stimulating greater strength and hypertrophy adaptations" [8].

The better the elderly physical fitness and hypokinetic status, will increase successful aging feeling for elderly. In this case Andrzej Knapik, et. al. describe: "This term (successful aging feeling) applies to the minimization of disease and infirmity, to the maintenance of optimal physical and mental fitness as well as the maintenance of the general life activity" [9].

\section{CONCLUSION}

There are differences in the effect of five sport activities idest lawn tennis, walking, table tennis, gymnastics, badminton against hypokinetic trends and risk for elderly.

\section{REFERENCES}

[1] S. Demura, S. Yamaji, Y. Nagasawa, S. Sato, M. Minami and Y. Yoshimura, "Reliability and gender differences of static explosive grip parameters based on force-time curves," J Sports Med Phys Fitness, vol. 43, no. 1, 2003.

[2] M. Król-Zielińska, K. Kusy, J. Zieliński and W. Osiński, "Physical activity and functional fitness in institutionalized vs. independently living elderly: A comparison of 70-80-year-old city-dwellers," Archives of gerontology and geriatrics, vol. 53, no. 1, pp. e10-e16, 2011.

[3] S. Giriwijoyo and D. Z. Sidik, Ilmu Kesehatan Olahraga. Bandung: PT Remaja Rosdakarya, 2012.

[4] J. Manson, M. Rotondi, V. Jamnik, C. Ardern, and H, Tamim, "Effect of tai chi on musculoskeletal health-related fitness and self-reported physical health changes in low income, multiple ethnicity mid to older adults," BMC geriatrics, vol. 13, no. 1, pp. 114, 2013.

[5] J. Lexell et al. "Physical Activity in the Prevention and Treatment of Disease," Department of Rehabilitation Medicine, Lund University Hospital, Division of Rehabilitation Medicine, Department of Clinical Sciences, Lund University, Lund, Sweden, 2017.

[6] D. P. Mood, A. W. Jackson, and J. R. Morrow Jr, Measurement of physical fitness and physical activity: Fifty years of change. Measurement in Physical Education and Exercise Science, vol. 11, no. 4, pp. 217-227, 2007.

[7] J. H. Suni, et al. "Health-Related Fitness Test Battery for Adults: Associations With Perceived Health, Mobility, and Back Function and Symptoms," Fitness And Musculoskeletal Function, Suni. Arch Phys Med Rehabil vol. 79, 1998.

[8] H. Arazi, "An Interaction between Exercise Order and Rest Interva during Lower-Body Resistance Exercise,” Baltic Journal Of Health And Physical Activity. (C) Gdansk University of Physical Education and Sport in Gdansk, vol. 4, no. 2, 2012, 77-83, 2012.

[9] A. Knapik, E. Saulicz, A. Mysliwiec, M. Saulicz and A. WarmuzWancisiewicz, "Motivations and effects of practicing Nordic Walking by elderly people," Baltic Journal of Health and Physical Activity, vol. 6 , no. 1 , pp. 34,2014 